\title{
Molecular Species Identification of Candida from Blood Samples of Intensive Care Unit Patients by Polymerase Chain Reaction - Restricted Fragment Length Polymorphism
}

\section{Ramraj Vijayakumar, Sidhartha Giri, Anupma Jyoti Kindo}

Department of Microbiology, Sri Ramachandra Medical College and Research Institute, Sri Ramachandra University, Porur, Chennai, India

Address for correspondence: Dr. Anupma Jyoti Kindo, E-mail: anupmalakra@yahoo.com

\section{ABSTRACT}

Introduction: Candida spp is an emerging cause of blood stream infections worldwide. Delay in speciation of Candida isolates by conventional methods and resistance to antifungal drugs (especially fluconazole, amphotericin B, etc.) in various Candida species are some of the factors responsible for the increase in morbidity and mortality due to candidemia. So, the rapid detection and identification of Candida isolates from blood is very important for the proper management of patients having candidemia.

Materials and Methods: In this study, we have used polymerase chain reaction (PCR) - restriction fragment length polymorphism (RFLP) as a method for the speciation of Candida isolates from blood samples of intensive care unit (ICU) patients. PCR was used to amplify the ITS-1 and ITS-2 regions of Candida spp using universal primers ITS-1 and ITS-4. The amplified product was digested using Msp I restriction enzyme by RFLP.

Results and Discussion: The method PCR-RFLP helped in identifying five medically important Candida spp (C. tropicalis, C. albicans, C. parapsilosis, C. krusei and C. glabrata) from blood. This method is rapid, reliable, easy and cost-effective and can be used in routine laboratory diagnostics for the rapid identification of Candida isolates from blood. Conclusion: PCR-RFLP is an easy, rapid and highly valuable tool which can be used in routine diagnostic laboratories to speciate Candida isolates obtained from blood. This rapid method of speciation will help clinicians to decide on empirical therapy in candidemia cases before antifungal susceptibility results are available.

Keywords: Candidemia, Msp I, polymerase chain reaction, restriction fragment length polymorphism

\section{INTRODUCTION}

andida species are the fourth leading cause of nosocomial blood stream infections (BSI) in the United States. The incidence and prevalence of candidemia is increasing in many other countries also. ${ }^{[1]}$ In India, the picture is not very clear due to lack of multicentric studies. Although, there are a few studies indicating the increasing trend of candidemia in some tertiary care hospitals. ${ }^{[2]}$ The mortality rate associated with candidemia worldwide is also high, ranging from $10-49 \% .^{[1]}$

\begin{tabular}{|l|l|}
\multicolumn{3}{c}{ Access this article online } \\
\hline Quick Response Code: & Website: \\
\hline & www.jponline.org \\
\hline & \\
\hline
\end{tabular}

More than 17 different species of Candida have been reported to be etiologic agents of invasive candidiasis in humans. Although more than $90 \%$ of invasive candidiasis is attributed to five species $C$. albicans, $C$. glabrata, C. tropicalis, C. parapsilosis and C. krusei, the list of reported species continues to grow. ${ }^{[1]}$ Although Candida albicans still remains the most common cause of candidemia worldwide, there has been an increase in the isolation of non-albicans Candida species. ${ }^{[1]}$ In the few available studies from India, Candida tropicalis has been the most common species of Candida isolated from blood. ${ }^{[2,3]}$

With the emergence of non-albicans species of Candida worldwide, especially Candida glabrata and Candida krusei, antifungal drug resistance has become a major cause of concern in the management of candidemia. Resistance to fluconazole and other triazoles is very high among these species of Candida. ${ }^{[4]}$ Other non- 
albicans Candida species like Candida tropicalis and Candida parapsilosis have been found to have variable susceptibility to the azole group of drugs. There have been a few reports of Candida species being resistant to amphotericin B and echinocandins also. ${ }^{[5,6]}$

A number of phenotypic methods have been developed for the speciation of Candida isolates which includes dalmau technique, sugar assimilation and fermentation, growth of characteristic colonies of various Candida species on tetrazolium reduction medium, CHROMagar etc. These standard phenotypic methods require about 48 to $72 \mathrm{~h}$ or sometimes even more for the speciation of Candida isolates and are also not very sensitive or specific.

The rapid detection and identification of Candida isolates from blood samples is very important for the proper management of patients having candidemia. The use of PCR as a method for diagnosis of candidemia has been proved to have a much greater sensitivity than these methods. ${ }^{[7]}$ Here we report the use of polymerase chain reaction - restricted fragment length polymorphism (PCR-RFLP) as a rapid, easy and cost-effective method for the rapid identification of five Candida species from blood isolates of ICU patients.

\section{MATERIALS AND METHODS}

Standard Strains: Candida glabrata obtained from National Culture Collection of Pathogenic Fungi (NCCPF), PGI (Chandigarh) and ATCC strains of Candida albicans (90028), Candida tropicalis (750), Candida parapsilosis (90018), and Candida krusei (6258) were used as a standard strains.

\section{Clinical isolates}

Totally 39 consecutive clinical isolates were collected from blood samples of patients from various intensive care units (ICUs) for a one-year period at Sri Ramachandra Medical Center, Chennai, Tamil Nadu, India. All the isolates were screened and identified using conventional culture and microscopic method. The isolates were cultured on Sabouraud's Dextrose Agar (SDA) and used for molecular analysis.

\section{DNA isolation}

DNA extraction was performed from all the clinical isolates and standard strains by in-house method. Briefly, $400 \mu \mathrm{l}$ of lysis buffer (10mM TRIS, pH - 8), $1 \mathrm{mM}$ EDTA $(\mathrm{pH}-8), 3 \%$ SDS and $100 \mathrm{mM} \mathrm{NaCl}$ ) was taken in a 1.5-ml centrifuge tube. A loop full of Candida culture was suspended in the lysis buffer and heated in water bath at $100^{\circ} \mathrm{C}$ for $1 \mathrm{~min}$. Equal volume of Phenol: Chloroform was added to it and mixed well. It was centrifuged at 10,000 rpm for $10 \mathrm{~min}$. The aqueous layer was transferred to a fresh centrifuge tube and the step was repeated once by adding chloroform to the supernatant. The DNA was precipitated by equal volume of cold isopropyl alcohol, centrifuged and washed with $70 \%$ ethanol. The pellet was re-suspended in $30 \mu \mathrm{l}$ of $\mathrm{TE}$ buffer and stored at $-20^{\circ} \mathrm{C}$ until use.

\section{PCR assay}

The master mix was prepared containing $25 \mu$ l of PCR mix (GeNei, Bangalore), $1 \mu$ l of forward (ITS-1) and reverse primer (ITS-4) (GeNei, Bangalore), $1 \mu$ l of template DNA and the volume made up to $50 \mu \mathrm{l}$ with sterile nucleasefree water. The reaction mix was kept in the thermocycler (Eppendorf). The program was performed as follows: initial denaturation at $95^{\circ} \mathrm{C}$ for $5 \mathrm{~min}$, denaturation at $95^{\circ} \mathrm{C}$ for $30 \mathrm{sec}$, annealing at $56^{\circ} \mathrm{C}$ for $30 \mathrm{sec}$, extension at $72^{\circ} \mathrm{C}$ for $30 \mathrm{sec}$ and final extension at $72^{\circ} \mathrm{C}$ for $5 \mathrm{~min}$.

\section{RFLP}

Two $\mu$ l of enzyme buffer, 5 Units of Msp I (GeNei, Banglore) enzyme and $10 \mu \mathrm{l}$ of PCR product were added in a 200- $\mu$ PCR tube and the volume was made up to $20 \mu \mathrm{l}$ with nuclease-free water. The reaction mix was incubated at $37^{\circ} \mathrm{C}$ for $1 \mathrm{~h}$.

\section{Agarose gel electrophoresis}

PCR products and RFLP products were electrophoresed in $1.5 \%$ and $2.0 \%$ agarose gel respectively, stained with Ethidium bromide $(0.5 \mu \mathrm{g} / \mathrm{ml})$ and visualized under UV light and photographed.

\section{RESULTS}

The PCR assay was able to amplify the ITS- 1 and ITS-2 region of all 39 isolates using universal primers ITS-1 and ITS-4. Amplicon size of 500-800bp was obtained from five medically important Candida species (C. tropicalis, $C$. albicans, C. parapsilosis, C. krusei and C. glabrata) [Figures 1a and 2a]. The restriction enzyme Msp I was used for RFLP technique as experimented by Mirhendi et al.,${ }^{\left[{ }^{[8}\right.}$ it produced two bands in each species except $C$. parapsilosis since it does not have restriction site specific for Msp I [Figure 1b and $2 b]$. The banding patterns are different from each other and hence it is easy to distinguish one species from another [Tables 1 and 2].

Journal of Laboratory Physicians / Jan-Jun 2012 / Vol-4 / Issue-1 


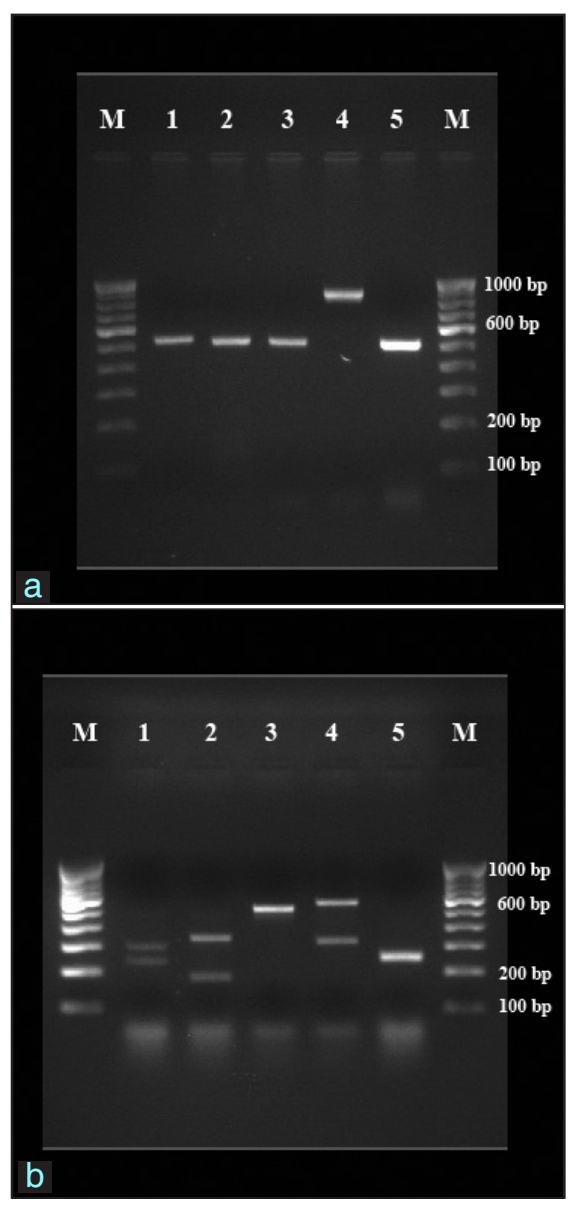

Figure 1: (a) PCR products from standard strains of Candida species. Lanes 1-5: C. albicans (ATCC 90028), C. tropicalis (ATCC 750), C. parapsilosis (90018), C. glabrata (pure strain from NCCPF) and $C$. krusei (6258), respectively. Lanes M: 100 bp DNA ladder. (b) RFLP products from standard strains of Candida species. Lanes 1-5: $C$. albicans (ATCC 90028), C. tropicalis (ATCC 750), C. parapsilosis (90018), C. glabrata (pure strain from NCCPF) and C. krusei (6258), respectively. Lanes M: 100 bp DNA ladder.

\section{DISCUSSION}

Rapid detection of Candida from blood stream infections is very essential for management of candidemia and to decrease the mortality rate associated with it. Currently used phenotypic methods may take 48 to $72 \mathrm{~h}$ to properly diagnose Candida isolates to the species level. Due to the limitations of phenotypic methods, molecular methods especially polymerase chain reaction (PCR) is being increasingly used for the rapid detection of Candida from blood. PCR has been found to have a much higher sensitivity in detecting candidemia than conventional phenotypic methods. ${ }^{[7]}$

Many other molecular methods have also been developed for the rapid diagnosis of Candida species like RAPD (Random amplified polymorphic DNA), DNA sequence

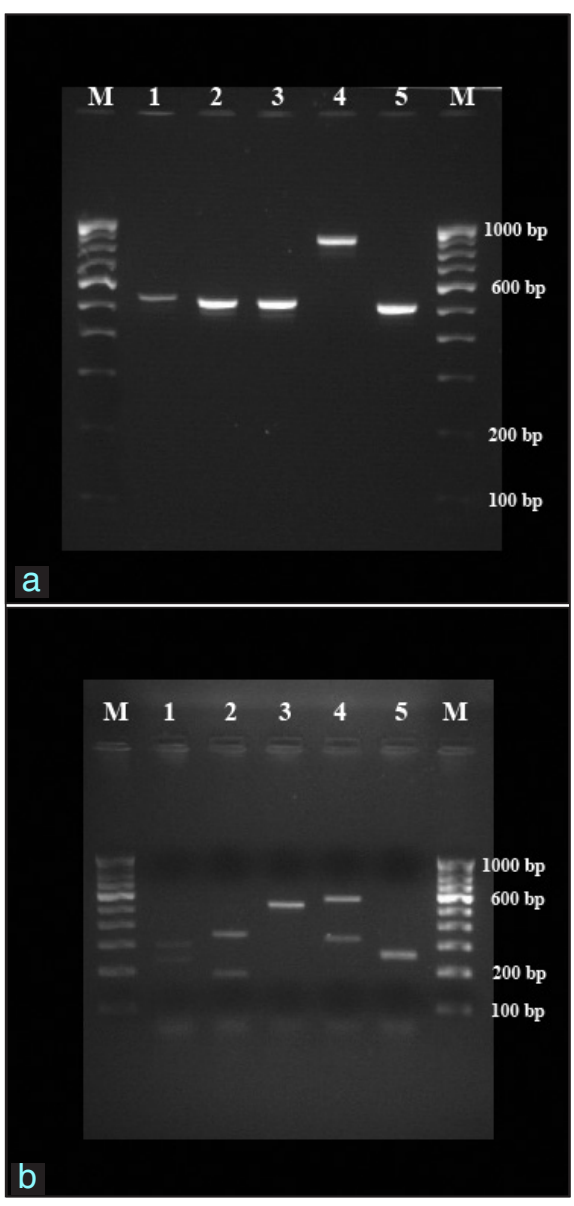

Figure 2: (a) PCR products from representative test strains of Candida species. Lanes 1-5: C. albicans, C. tropicalis, C. parapsilosis, $C$. glabrata and C. krusei, respectively. Lanes M: 100 bp DNA ladder. (b) RFLP products from representative test strains of Candida species. Lanes 1-5: C. albicans, C. tropicalis, C. parapsilosis, C. glabrata and C. krusei, respectively. Lanes M: 100 bp DNA ladder.

\begin{tabular}{|c|c|c|}
\hline \multicolumn{3}{|c|}{$\begin{array}{l}\text { Table 1: Size of ITS1-ITS2 products for Candid } \\
\text { species before and after digestion with Msp I }\end{array}$} \\
\hline $\begin{array}{l}\text { Candida } \\
\text { species }\end{array}$ & $\begin{array}{l}\text { Size of ITS1-ITS2 } \\
\text { product (bp) }\end{array}$ & $\begin{array}{l}\text { Size of restriction product } \\
\text { (bp) }\end{array}$ \\
\hline C. albicans & 535 & 297,238 \\
\hline C. tropicalis & 524 & 340,184 \\
\hline C. glabrata & 871 & 557,314 \\
\hline C. krusei & 510 & 261,249 \\
\hline C. parapsilosis & 520 & 520 \\
\hline
\end{tabular}

Table adapted from Mirhendi et $a l^{\left[{ }^{[8]}\right.}$

\begin{tabular}{|c|c|}
\hline Candida species & Number (\%) \\
\hline C. tropicalis & $29(74 \cdot 35 \%)$ \\
\hline C. albicans & $4(10.25 \%)$ \\
\hline C. parapsilosis & $3(7.69 \%)$ \\
\hline C. krusei & $2(5.13 \%)$ \\
\hline C. glabrata & $1(2.56 \%)$ \\
\hline Total & $39(100 \%)$ \\
\hline
\end{tabular}


analysis, mitochondrial large subunit ribosomal RNA gene sequencing and real-time PCR. ${ }^{[9-11]}$ But these methods are expensive and need skilled workers trained in such techniques.

In our study, PCR-RFLP was done for 39 Candida isolates from blood samples of ICU patients. The ITS1-5.8S-ITS2 rDNA region from genomic DNA of several species of Candida was amplified by PCR. RFLP was done for the amplified products using the Msp I restriction enzyme. All the isolates were correctly identified to the species level. Five species of Candida were detected from blood isolates of ICU patients in our study (C.tropicalis, C. albicans, C. parapsilosis, C. glabrata, C. kruse ).

PCR-RFLP has been found to be a rapid and reliable method to speciate Candida isolates in other studies also. In a study by Shokohi et al., from Iran, Candida species have been identified in cancer patients by PCR-RFLP using two restriction enzymes (Bln I, Msp I). ${ }^{[12]}$ In another similar study from Iran, Mirhendi et al., have developed a one-enzyme PCR-RFLP assay for identification of six medically important Candida species. ${ }^{[8]}$ PCR-RFLP has also been used to speciate Candida isolates causing intraocular infections by Okhravi et al. ${ }^{[13]}$

In our study, we found PCR-RFLP to be a rapid, easy to handle and cost-effective procedure which can be used to speciate Candida isolates from blood samples. The whole procedure of PCR-RFLP from Candida isolates can be completed within $7 \mathrm{~h}$ as compared to $48-72 \mathrm{~h}$ needed for phenotypic methods to speciate the isolates. This will give clinicians valuable time to decide on the empirical treatment of candidemia before antifungal sensitivity reports are available. For example, C. krusei is intrinsically resistant to fluconazole and C. glabrata is also usually resistant to fluconazole. So, patients having candidemia caused by such species can be started empirically on amphotericin $\mathrm{B}$ or echinocandins.

\section{CONCLUSION}

PCR-RFLP is an easy, rapid and highly valuable tool which can be used in routine diagnostic laboratories to speciate
Candida isolates obtained from blood. This rapid method of speciation will help clinicians to decide on empirical therapy in candidemia cases before antifungal susceptibility results are available.

\section{REFERENCES}

1. Pfaller MA, Diekema DJ. Epidemiology of Invasive Candidiasis: a Persistent Public Health Problem. Clin Microbiol Rev 2007;20:133-63.

2. Xess I, Jain N, Hasan F, Mandal P, Banerjee U. Epidemiology of candidemiain a tertiary care centre of north India: 5-year study. Infection 2007;35:256-9.

3. Sahni V, Agarwal SK, Singh NP, Anuradha S, Sikdar S, Wadhwa A, et al. Candidemia - An Under-recognized Nosocomial Infection in Indian Hospitals. J Assoc Physicians India 2005;53:607-11.

4. Pfaller MA, Diekema DJ; International Fungal Surveillance Participant Group. Twelve years of fluconazole in clinical practice: global trends in species distribution and fluconazole susceptibility of bloodstream isolates of Candida. Clin Microbiol Infect 2004;10 Suppl 1:11-23.

5. Nolte FS, Parkinson T, Falconer DJ, Dix S, Williams J, Gilmore C, et al. Isolation and characterization of fluconazole and amphotericin B-resistant Candida albicans from blood of two patients with leukemia. Antimicrob Agents Chemother 1997;41:196-9.

6. Krogh-Madsen M, Arendrup MC, Heslet L, Knudsen JD. Amphotericin $\mathrm{B}$ and caspofungin resistance in Candida glabrata isolates recovered from a critically ill patient. Clin Infect Dis 2006;42:938-44.

7. Ahmad S, Khan Z, Mustafa AS, Khan ZU. Seminested PCR for diagnosis of candidemia: comparison with culture, antigen detection, and biochemical methods for species identification. J Clin Microbiol 2002;40:2483-9.

8. Mirhendi H, Makimura K, Khoramizadeh M, Yamaguchi H. A One-Enzyme PCR-RFLP assay for identification of six medically important Candida species. Nihon Ishinkin Gakkai Zasshi 2006;47:225-9.

9. Yamada Y, Makimura K, Uchida K, Yamaguchi H, Osumi M. Phylogenetic relationships among medically important yeasts based on sequences of mitochondrial large subunit ribosomal RNA gene. Mycoses 2004;47:24-8.

10. Sugita T, Nishikawa A. Molecular taxonomy and identification of pathogenic fungi based on DNA sequence analysis. Nippon Ishinkin Gakkai Zasshi 2004;45:55-8.

11. White PL, Shetty A, Barnes RA. Detection of seven Candida species using the Light-Cycler system. J Med Microbiol 2003;52:229-38.

12. Shokohi T, Soteh MB, Saltanat Pouri Z, Hedayati MT, Mayahi S. Identification of Candida species using PCR-RFLP in cancer patients in Iran. Indian J Med Microbiol 2010;28:147-51.

13. Okhravi N, Adamson P, Mant R, Matheson MM, Midgley G, Towler $\mathrm{HM}$, et al. Polymerase chain reaction and restriction fragment length polymorphism mediated detection and speciation of Candida spp causing intraocular infection. Invest Ophthalmol Vis Sci 1998;39:859-66.

How to cite this article: Vijayakumar R, Giri S, Kindo AJ. Molecular species identification of candida from blood samples of intensive care unit patients by polymerase chain reaction - Restricted fragment length polymorphism. J Lab Physicians 2012;4:1-4.

Source of Support: Nil. Conflict of Interest: None declared. 